\title{
EFEITOS DOS COMUNICADOS GOVERNAMENTAIS SOBRE SAÚDE EM TEMPOS DE PANDEMIA NOS ALUNOS DE 3OS ANOS DO ENSINO MÉDIO DE JUIZ DE FORA
}

\author{
C. P. DUARTE \\ Universidade Federal de Juiz de Fora \\ ORCID ID: $\underline{\text { https://orcid.org/0000-0003-3671-0867 }}$ \\ catia.duarte@ufjf.edu.br
}

Submetido 14/03/2020 - Aceito 14/12/2020

DOI: 10.15628/holos.2020.11049

\begin{abstract}
RESUMO
Após meses de desafios para enfrentar a pandemia pelo novo coronavírus, os alunos formandos do Ensino Médio de escolas públicas e privadas de Juiz de Fora vêm adoecendo com a nova rotina do ensino remoto emergencial. Frente a este cenário, de que forma os comunicados governamentais de alguns Ministérios têm impactado a constituição do corpo juvenil, enquanto fato social total, para continuar os estudos durante o distanciamento social? Pretende-se, então, por meio deste artigo, analisar: como os estudantes interpretam as mensagens das autoridades divulgadas nas redes sociais
\end{abstract}

e como ressignificam os sonhos e as angústias durante a pandemia. A partir de um levantamento exploratório em quatro grupos de formandos, com análise de conteúdo de respostas de um questionário aberto em forma de software aplicado por WhatsApp, 66 estudantes se manifestaram sobre os efeitos do momento nas suas vidas estudantis, dando indícios de que há um projeto governamental para a intelectualidade juvenil brasileira e que este pode causar danos físicos e psicológicos a jovens de algumas classes sociais.

PALAVRAS-CHAVE: comunicados governamentais, pandemia, saúde dos formandos do Ensino Médio.

\section{EFFECTS OF THE GOVERNMENTAL COMMUNICATES REGARDING HEALTH IN THE PANDEMIC PERIOD ON STUDENTS OF THE THIRD YEAR OF HIGH SCHOOL IN JUIZ DE FORA}

\begin{abstract}
After challenging months dealing with the new coronavirus pandemic, high school students from public and private institutions of Juiz de Fora are getting sick by the new routine of emergency remote education. In this context, how have government communications from some Ministries impacted the constitution of the youth body, as a total social fact, to continue their studies during social distance? It is intended through this paper to analyze: how students interpret the messages from authorities disclosed on social networks and how they
\end{abstract}

redefine dreams and anguish during the pandemic. From an exploratory survey in four groups of pupils, with content analysis of the responses from an open questionnaire in software form applied by WhatsApp, 66 students expressed their opinion on the effects of the moment on their student lives, giving evidence that there is a government project for the Brazilian youth intellectuality and that it can cause physical and psychological damage to young people from some social classes.

KEYWORDS: governmental communicates, pandemic, health of high school graduates. 


\section{INTRODUÇÃO}

Na história, a ciência causou muitos avanços e retrocessos, pois determinadas descobertas científicas do século XX, higienizaram, literalmente, a população, matando pessoas como se fossem vírus. Estes estímulos foram justificados a partir dos trabalhos do inglês Francis Galton (1865), que, baseando-se na premissa de que o talento e o caráter poderiam ser passados geneticamente, influenciou pesquisadores a filiarem-se à ideia do desenvolvimento moral dos povos por meio de cruzamentos estratégicos. Por ter cunhado o termo eugenia (teoria que busca produzir uma seleção nas coletividades humanas), este autor foi acusado de preconceito de classe, sugerindo a eliminação de algumas raças (Cont, 2008). Tal sugestão segregou pessoas pelas condições de saúde e pelo empobrecimento intelectual, pois não bastava apenas o controle socioeconômico por parte dos governantes - era fundamental o controle sociopolítico das gerações ${ }^{1}$.

Em abril, com a pandemia pelo novo coronavírus, foi necessário fechar o comércio para que as famílias ficassem em casa. O Congresso brasileiro aprovou um auxílio emergencial (Kafruni, 2020), no entanto, o presidente estimulava a reversão da ação porque o vírus acometeria a pessoa a apenas uma gripezinha (Martins, 2020a). A ciência brasileira passou a sofrer desmontes com o presidente atual ridicularizando o Instituto Nacional de Pesquisas Espaciais (INPE) (Rodrigues, 2019); cortando bolsas de pesquisas (Jucá, 2019); bloqueando o orçamento das universidades (Oliveira, 2019); tentando mudar a bula do medicamento cloroquina por decreto, apesar das várias autoridades da área da saúde, de diferentes nacionalidades, atestarem a ineficiência e riscos do uso desse fármaco (Rede TVT, 2020); desmerecendo as ciências humanas e sociais, pela Portaria n o 1.122, de 19 de março de 2020, do Ministério da Ciência, Tecnologia, Inovações e Comunicações, retirando a área das prioridades de projetos de pesquisa do Conselho Nacional de Pesquisas (CNPq) até 2023.

Segundo Foucault (1979), o poder ${ }^{2}$ reprime, mas também produz efeitos de saber e verdade. Neste tempo e espaço histórico, é importante "captar o poder nas suas formas e instituições mais regionais e locais, principalmente no ponto em que ultrapassam as regras de direito que o organizam e delimitam" (p. 182). As relações de poder são tão complexas que, por vezes, encontram-se discursos governamentais pretenciosos da coletividade, mas que passam o direito e a verdade para responsabilidade individual. Diante dos papéis possíveis que a sociedade pode apresentar, Foucault (2008) nos apresenta duas tecnologias de poder: uma técnica que é centrada no corpo com efeitos individualizantes, manipulando o corpo para ser útil e dócil ao mesmo tempo; e, uma tecnologia que é centrada na vida com efeitos nas massas, próprios para a população. Neste interim, os jovens constroem suas subjetividades.

\footnotetext{
${ }^{1} \mathrm{O}$ atraso e o abandono dos estudos fazem com que boa parte dos trabalhadores não atenda as demandas do mercado e, por isso, ficam limitados a atividades operacionais, de menor complexidade e com remuneração inferior. Neste interim, movimentos políticos sociais (Mendonça, Correio \& Correio, 2016) podem proteger a saúde dos jovens trabalhadores e/ ou jovens estudantes a caminho de diferentes mobilidades sociais.

2 Potere, substituído ao latim clássico posse, que vem a ser a contração de potis esse ou "ser capaz"; "autoridade". Dessa forma, na prática, a palavra poder torna-se a ação que exprime força, persuasão, controle, regulação (idem, ibidem).
} 
Enquanto morriam mais de mil pessoas por dia, ministros não se comprometeram com seus cargos, sugerindo um tipo de ensino que segue o modelo de Ensino a Distância ${ }^{3}$ (EaD) para substituir o ensino anterior à pandemia, desconsiderando: uma produção de conhecimento existente sobre esse modelo de educação no Brasil; estudos que definiram a ilegalidade do modelo até os 9ㅇ anos do Ensino Fundamental no passado; e, um diagnóstico socioeconômico da população. Vale lembrar Bourdieu (1992) quando resgatou que, desde os anos 60, houve uma crise em relação à concepção de escola e uma reinterpretação radical do papel dos sistemas de ensino na sociedade, porque o desempenho escolar não dependia de dons, mas da classe, etnia, sexo, local de moradia dentre outros aspectos.

Ao ficar em casa e acompanhar o mundo pelas redes sociais ou plataformas de estudo, os estudantes se protegem do vírus, porém, se não souberem usar as redes sociais, podem ter transtornos físicos e mentais nos indivíduos que se excederem na cibercultura ${ }^{4}$. Salas (2017) concluiu que o Instagram, seguido por Snapchat, Facebook e Twitter poderia possuir impacto nocivo na saúde mental de jovens e Zajac (2020) afirmou que aqueles que vivem sem acesso à internet não têm educação de qualidade no ensino remoto emergencial ${ }^{5}$ (ERE).

Assim, de que forma os comunicados governamentais de alguns Ministérios têm impactado a constituição do corpo juvenil, enquanto fato social total - maneiras de ser e agir, compreendendo as diferentes modalidades do social, da própria história individual e das diferentes formas de expressão (Mauss, 2017)-, para continuar os estudos durante o distanciamento social? A resposta sinaliza o pressuposto de que há um projeto governamental para a intelectualidade juvenil brasileira e que este pode causar danos físicos e psicológicos aos jovens de algumas classes sociais. Para responder à questão, pretende-se analisar: como os estudantes interpretam as mensagens das autoridades divulgadas nas redes sociais e como ressignificam as angústias e os sonhos de realização profissional durante a pandemia em Juiz de Fora (JF).

\section{PROCEDIMENTOS METODOLÓGICOS}

A partir de uma pesquisa exploratória, com levantamento das questões objetivas deste estudo em quatro grupos ${ }^{6}$ de formandos do EM, fez-se uma comparação das respostas a um questionário em forma de software, aplicado por WhatsApp. A pesquisa exploratória proporciona

\footnotetext{
${ }^{3}$ Mesmo o Ministério da Educação (MEC) estar amparado pela legislação a qual indica que o ensino fundamental seja presencial (Lei n. 9.394, 1996) e que o EaD seja uma complementação de aprendizagem, seus líderes se valeram da situação emergencial para autorizar essa prática complementar por trinta dias ou mais (Portaria n. 343, 2020), o risco à saúde pública não poderia ferir o princípio constitucional que garante, em seu artigo 205, o direito de todos à educação de qualidade (Constituição da República Federativa do Brasil, 1988).

${ }^{4}$ Cultura que surge do uso de computadores e outros suportes tecnológicos (smartphone, por exemplo) para manter comunicação virtual, entretenimento e comércio eletrônico (Vermelho, Velho, Bonkovoski \& Pirola, 2014).

${ }^{5}$ Mesmo o Ministério da Educação (MEC) estar amparado pela legislação, a qual indica que o ensino fundamental seja presencial (Lei n. 9.394, 1996) e que o EaD seja uma complementação de aprendizagem, seus gestores se valeram da situação emergencial para autorizar essa prática complementar por trinta dias ou mais (Portaria n. 343, 2020), e o risco à saúde pública não poderia ferir o princípio constitucional que garante, em seu artigo 205, o direito de todos à educação de qualidade (Constituição da República Federativa do Brasil, 1988).

${ }^{6}$ Em junho de 2020, as escolas públicas estavam se preparando para o início do ensino remoto emergencial, enquanto as escolas particulares já estavam no modelo de ensino desde abril.
}

HOLOS, Ano 36, v.5, e11049, 2020 
maior familiaridade do pesquisador com um problema que observa no seu cotidiano - no caso, da professora de 3 EM com seus alunos-, a fim de construir pressupostos que colaborem com o processo de ensino neste momento histórico. Dentre diversos procedimentos técnicos cabíveis, fez-se um levantamento para saber a opinião dos alunos sobre o tema em questão, com a vantagem de revelar a realidade com economia, rapidez e quantificação, mas com a desvantagem de dar ênfase aos aspectos perceptivos dos sujeitos ou pouca profundidade das questões no momento de validação do estudo ${ }^{7}$ e da coleta de dados (Gil, 2009). Após este momento, fez-se um trabalho comparativo (Bruyne, Herman \& Schoutheete, 1977) entre as respostas advindas do questionário aberto, sendo este um instrumento de coleta de dados composto por um número mais ou menos elevado de questões, tendo por objetivo o conhecimento de opiniões, sentimentos, interesses, expectativas ou situações vivenciadas (Gil, 2009), podendo ser aplicado por rede social, ideal em períodos que exigem distanciamento social.

No grupo de pesquisa "Práticas escolares e Educação Física" da Universidade Federal de Juiz de Fora se desenvolve trabalhos com professores de todas as redes de ensino e, assim, organizou-se um quadro com dois perfis de estudantes para os quatro grupos de formandos, de acordo com o recebimento, ou não, do ERE. Dos grupos, que somaram 132 estudantes, apenas a metade $^{8}$ respondeu o instrumento de coleta de dados conforme discriminado na Tabela 1:

Tabela 1: Perfil da amostra9

\begin{tabular}{c|c|c|c}
\hline Tipo de escola & Idade & $\begin{array}{c}\text { Turno de estudo } \\
\text { e local de } \\
\text { moradia }\end{array}$ & $\begin{array}{c}\text { Horário de trabalho e de } \\
\text { estudo fora do horário } \\
\text { regular }\end{array}$ \\
\hline $\begin{array}{c}48 \text { alunos de três } \\
\text { processo de ERE }\end{array}$ & $2 / 3$ possui 17 anos & $\begin{array}{c}\text { Estudam pela } \\
\text { manhã e } \\
\text { moram nos } \\
\text { mais diversos } \\
\text { bairros da } \\
\text { cidade }\end{array}$ & $\begin{array}{c}5 \% \text { trabalha no } \\
\text { contraturno e faz } \\
\text { cursinhos pré- } \\
\text { vestibulares pagos }\end{array}$ \\
\hline
\end{tabular}

\footnotetext{
${ }^{7}$ Agradecimentos à Profa. de Comunicação, Dra. Iluska Maria da Silva Coutinho; à Profa. de Sociologia, Dra. Joana Brito de Lima Silva; ao Prof. de Filosofia, Dr. Luciano Donizetti da Silva; e, à Assistente Social do Colégio de Aplicação João XXIII (CAp) de JF, Ana Vargas, pelas contribuições dadas ao instrumento de coleta de dados. Ainda se agradece os quinzes alunos gaúchos que, com os mesmos perfis da amostra, contribuiu com os pesquisadores ao responder e criticar o questionário. A partir desses diálogos, perceberam-se os pontos positivos da técnica de análise de conteúdo: verificação dos membros, exames dos pares, esclarecimento dos viesses identificados pelos pesquisados (Mozzato \& Grzybovski, 2011).

${ }^{8}$ Dos 66 respondentes, em sua maioria branca e parda, 2/3 são mulheres. A maioria dos pais de alunos de escola particular concluiu o ensino médio, enquanto a maioria dos pais de alunos de escolas públicas concluiu o ensino fundamental.

${ }^{9}$ Vale frisar que as porcentagens se dão entre o grupo que não teve ensino remoto (48 alunos de escolas públicas entre si equivalendo $100 \%$ ) e o que está usufruindo do modelo desde o início da pandemia (18 alunos de escola privada entre si equivalendo $100 \%)$.
}

HOLOS, Ano 36, v.5, e11049, 2020 


\begin{tabular}{c|c|c|c}
\cline { 2 - 4 } & $\begin{array}{c}\text { 1/3 possui, em } \\
\text { média, 27 anos } \\
\text { particular em ERE }\end{array}$ & $\begin{array}{c}\text { Estudam à noite } \\
\text { e moram em } \\
\text { bairros } \\
\text { próximos das } \\
\text { escolas }\end{array}$ & $\begin{array}{c}\text { 95\% trabalha no } \\
\text { contraturno e não faz } \\
\text { cursinhos }\end{array}$ \\
\hline Têm 17 anos & $\begin{array}{c}\text { Estudam pela } \\
\text { manhã e } \\
\text { moram em } \\
\text { diferentes } \\
\text { bairros da } \\
\text { cidade }\end{array}$ & $\begin{array}{c}\text { Não trabalham nem } \\
\text { fazem cursinhos } \\
\text { porque recebem } \\
\text { reforços para os } \\
\text { exames de final de } \\
\text { ano no contraturno }\end{array}$ \\
\hline
\end{tabular}

Para tanto, usou-se a técnica de análise do conteúdo (Bardin, 2006), para realizar 1) préanálise ${ }^{10}, 2$ ) exploração do material ${ }^{11}$ e 3) tratamento dos resultados, inferência e interpretação ${ }^{12}$. Para aprofundar este terceiro ponto, optou-se por não apresentar os detalhamentos das etapas anteriores.

\section{ANÁLISE DOS DADOS}

De acordo com o tratamento dos resultados, apresentam-se as categorias de respostas dos sujeitos e suas inferências e interpretações.

A análise sobre os reflexos da pandemia no cotidiano do aluno trouxe dados preocupantes: $21 \%$ dos estudantes das escolas pública e $56 \%$ do grupo das escolas particular revelaram ter sensações de impotência e tristeza; $61 \%$ dos alunos de escolas públicas demonstraram estar assustados/com medo/ preocupados/incomodados; $17 \%$ da rede pública e $22 \%$ da rede particular manifestou reação de ansiedade com desmotivação. Esses números demonstram como a pandemia afetou, de diferentes formas, a saúde mental dos grupos estudados. Perceber isso é fundamental, afinal, a saúde mental pode acabar negligenciada perante a maior preocupação com o patógeno e com o risco biológico (Ornell, Schuh, Sordi \& Kessler, 2020).

Dando continuidade às análises, $17 \%$ da rede pública e $22 \%$ da particular demonstrou raiva com base na constatação de que o Ministério da Educação supõe que todos possuem a mesma

\footnotetext{
${ }^{10}$ Trata-se da organização propriamente dita por meio de quatro etapas: leitura flutuante; escolha dos documentos que serão analisados; formulação das hipóteses e dos objetivos; determinação de indicadores por meio de recortes de texto nos documentos de análise (Bardin, 2006).

${ }^{11}$ Consiste na primeira categorização com definição de unidades de registro por temas, com núcleos de sentido próximos (reflexos da pandemia; quem tem autoridade para falar de saúde e de educação; relação dos comunicados com as perspectivas de vida; assuntos que chamam atenção no distanciamento social; horas de internet e empenho com ERE; sonhos e angústias daqui pra frente). Depois, identificaram-se as unidades de contexto nos documentos para que fosse possível discutir as unidades de registro de acordo com o referencial escolhido. Por fim, fez-se uma segunda categorização com classificação das palavras segundo seus sentidos ou sinônimos, a partir de exclusão das ambiguidades para calcular as frequências; pertinência dos tópicos com o quadro teórico definido; objetividade e fidelidade do elemento categorizado; produtividade que permite índices de inferências (Urquiza \& Marques, 2016).

${ }^{12}$ Consiste no tratamento dos resultados, inferência e interpretação, onde ocorre a condensação e o destaque das informações para análise, culminando nas interpretações inferenciais; é o momento da intuição, da análise reflexiva e crítica (Bardin, 2006).
}

HOLOS, Ano 36, v.5, e11049, 2020 
condição de acesso à internet, quando, na verdade, a maioria dos estudantes de EM das escolas públicas não têm computador em casa (Zajac, 2020). Os dados obtidos a partir do estudo apontam ainda que $4 \%$ da escola pública e $11 \%$ da escola particular revelaram ter se acostumado, enquanto um estudante da instituição pública sinalizou culpa por ter condições de estudar em qualquer situação de saúde pública. Desde o golpe parlamentar jurídico-midiático (Zan \& Krawczyk, 2020), ocorrido em 2016, no Brasil, tem-se atravessado um período de desmonte de políticas públicas e de retrocessos nos direitos sociais recentemente conquistados; no entanto, como os jovens manifestam interesse em continuar as comunicações via internet, digital ou on-line, é necessário identificar o que precisa ser dito e rever como veicular ou disponibilizar as formações civis nas redes.

Questionados sobre quem estaria qualificado a dar notícias sobre temas relacionados à saúde, $87 \%$ dos estudantes da escola pública e $67 \%$ da particular responderam que seriam os profissionais da saúde; $9 \%$ da escola pública e $11 \%$ da particular afirmaram que seriam entidades internacionais de saúde; $13 \%$ do grupo da escola pública revelou não saber. Questionados sobre quem está autorizado a dar notícias sobre educação, um grupo de $12 \%$ de alunos de escolas públicas e $11 \%$ da particular não soube responder. Outros $88 \%$ de alunos de escolas públicas e $89 \%$ de alunos da escola particular responderam que as autoridades no assunto são os profissionais qualificados da educação; e, ainda, $9 \%$ dos respondentes de escolas públicas sinalizaram, também, serem autoridades os órgãos de Educação. Chama atenção que a maioria dos alunos dos dois grupos ainda tem dificuldade para compreender a importância das entidades governamentais em um período de distanciamento social, o qual exigiria tanto providências administrativas quanto pedagógicas e que os de JF ainda não relacionam as pessoas às suas representações institucionais.

Esta realidade vai ao encontro da teoria de Foucault (2008) quando critica o panoptismo (máquina que, a partir dos desejos mais diversos, fabrica efeitos homogêneos de poder) das instituições, afirmando que, por meio da linguagem, comportamento e valores, aprisionam-se os sujeitos. A política que conduz tais instituições depende de uma disciplina que distribui os indivíduos no espaço e isso acontece quando o sujeito se sente representado ou não, pois interessa o controle e as roupagens só são trocadas, permanecendo no controle. O problema é que, em distanciamento social, ninguém sabe ao certo, como garantir o poder da verdade sobre o conhecimento, restando então, um ganho de força com o discurso sobre a utilidade das tecnologias, por um lado, e a perda de força da sua sujeição à obediência política, por outro.

Esse dilema recebe luz quando os jovens exemplificam os motivos que os deixam inseguros. Mesmo com as datas do Programa de Ingresso Seletivo Misto (PISM) e o Enem postergadas, o currículo escolar se modificou sem ter um projeto político-pedagógico (PPP) que o embasasse nas novas metodologias de ensino. Vinte e cinco por centro dos alunos de escolas públicas e da particular estão preocupados com o futuro do Enem. Vale registrar o movimento estudantil \#AdiaEnem representou os alunos brasileiros frente a comunicados problemáticos dos Ministros da Educação, porém, o número elevado dos alunos de escola pública que ainda não se envolveu com o ERE vem aumentando a cada mês que os alunos precisam trabalhar, sem opção pela continuidade dos estudos (Zan \& Krawczyk, 2020). 
Outra preocupação é com o aumento da desigualdade social, $20 \%$ dos alunos de escolas públicas e $35 \%$ da particular entende que será difícil mudar a realidade em um curto espaço de tempo (Zajac, 2020), a começar pela metade dos sujeitos desta pesquisa que, mesmo vendo o link no celular, não conseguiu responder o questionário no período que o mesmo estava disponível, por não ter acesso à internet. Quinze por cento dos alunos de ambas as escolas frisam o descaso governamental. Tentando instigar mais insegurança, os planos do governo, segundo Pimentel (2018), mais assustam do que tranquilizam a população: não admissão de ideologia de gênero; proposição da diminuição do percentual de vagas para cotas raciais; adoção da educação à distância no Ensino Fundamental para combater o marxismo.

Governar um Estado está associado a uma vigilância tão atenta quanto à do pai de família e não a produção de reflexão crítica da população (Foucault, 1979). Quando os $10 \%$ de alunos de escolas públicas e $15 \%$ da particular registram que é preciso unidade das escolas para traçar a futuro da educação, eles clamam para que a sociedade caminhe em um sentido que respeite o art. n. 206 da Constituição (Constituição da República Federativa do Brasil, 1988), quando esta salienta que educar é garantir aos jovens o seu pleno desenvolvimento com base na igualdade de condições de acesso e permanência na escola. Infelizmente, 30 \% de escolas públicas e $12 \%$ da particular não se manifestaram sobre os motivos que os deixavam incomodados.

Mesmo sinalizando preocupação com a desigualdade social, percebeu-se que $35 \%$ dos estudantes de escolas públicas e $44 \%$ da particular se comunicam e se informam pelo Facebook; $61 \%$ dos estudantes de escolas públicas e $67 \%$ da particular usam WhatsApp; $57 \%$ dos estudantes de escolas públicas e $22 \%$ da particular usam Twitter; $48 \%$ das públicas e $44 \%$ da particular, Youtube; $26 \%$ das públicas e $56 \%$ da particular, Instagram. Essa realidade tem contribuído de alguma forma com a educação, mas, também, gerado informações distorcidas acerca da realidade sobre diversos aspectos do Brasil e do mundo. Esse fato preocupa docentes (Vermelho et al, 2014), porque muitos alunos propagam um discurso de que não é necessário estar na escola para adquirir conhecimentos ou que a internet dá respostas rápidas às perguntas mais complexas de seu momento histórico (Salas, 2017). Esta busca pelas redes sociais foi possível porque se detectou que $87 \%$ dos alunos das escolas públicas e $80 \%$ da particular têm banda larga, enquanto $13 \%$ dos alunos das escolas públicas só têm dados móveis e $20 \%$ da particular também têm dados móveis.

Na relação entre as horas de estudo (através de acesso à internet) e o nível de estresse, destacou-se que, dentre os estudantes que estudam mais de quatro horas - após usar um tempo na internet para outros fins-, $22 \%$ da escola pública e $58 \%$ da escola particular manifestam sentimentos de incompetência, tristeza ou apatia. Outros $12 \%$ de alunos de escolas públicas e $22 \%$ da particular manifestam raiva incontrolada. Chamou a atenção que $48 \%$ dos estudantes da escola pública se sentem assustados; $12 \%$ dos estudantes das escolas públicas e $20 \%$ dos estudantes da particular aumentaram o nível de ansiedade. Nesse sentido, ter acesso à internet permite que o aluno se envolva com as informações do mundo. Por outro lado, o tempo necessário para estudar o que está sendo proposto pelo ERE levará estudantes a ter sérios problemas físicos, como sequelas na coluna vertebral e nas extremidades dos membros superiores (Duarte \& Fernandes Jr., 2019), bem como graves transtornos psíquicos (Polanczyk, 2020). 
A investigação sobre os temas que mais chamam a atenção dos jovens nas redes sociais indicou que a saúde foi apontada por $39 \%$ dos estudantes das escolas públicas e por $33 \%$ da particular. Já a política foi indicada por $4 \%$ da rede pública e por $33 \%$ da particular. Assuntos gerais tiveram uma preferência de $61 \%$ da escola pública e $22 \%$ da particular. Não sabem e/ou não responderam $3 \%$ da escola pública e $12 \%$ da particular. Estes dados revelaram que a temática da saúde tem capacidade de mobilizar o público de ambas as instituições escolares. Todavia, descobrimos um notável distanciamento do grupo da escola pública com relação a assuntos ligados à política. Neste sentido, Mendonça et al (2016) alerta que os jovens estão frustrados com a imagem de políticos corruptos e, por isso, se afastam da política, como se fosse política partidária.

Resgatando Foucault (1979), entende-se que a arte de governar tem sequências ascendentes e descendentes. Para alguém governar, deve primeiro convencer os outros de que sabe se governar. As famílias demonstram que entendem o funcionamento do Estado ao fazer boas escolhas de seus representantes. Por outro lado, quando o Estado é bem governado, os pais de família governam seus bens e seus familiares. Quando o governo de si (a moral), o governo de Estado (a política) e o governo da família (a economia) estão equilibrados, cria-se uma sociedade menos individualista; quando não estão, cria-se uma sociedade alienada e, portanto, a mercê do que decidirem para ela. Sem total esclarecimento do que poderia ocorrer a curto, médio e longo prazo, o ERE convenceu pela necessidade da ação imediata. Resgatando Mauss (2017) quando traz a relação entre os fatos da antropologia social e a interpretação das palavras, ações e produções imaginárias de um indivíduo, percebe-se a excitabilidade de aceitação ou resistência de cada grupo (o esforço, a dor, o prazer são menos função de particularidades individuais do que critérios sancionados pela aprovação ou desaprovação coletivas) de acordo com o medo de se manter nas atuais condições socioeconômicas.

Bourdieu (1998) colabora com a discussão, frisando a importância da bagagem socialmente herdada de cada indivíduo, já que certos componentes objetivos e externos ao indivíduo, podem ser postos a serviço do sucesso escolar (capital econômico, o capital social, capital cultural). A bagagem transmitida pela família inclui, por outro lado, certos componentes que passam a fazer parte da própria subjetividade do indivíduo na sua forma incorporada. Com isso, a chamada cultura geral oferece um domínio maior ou menor das informações sobre o mundo escolar e assim, se ficar sob o controle exclusivo do jovem, ficará incompleto.

A análise dos dados que envolvem os sonhos e as pretensões profissionais do público estudado revela que $75 \%$ do grupo da escola pública e $64 \%$ da escola particular ambiciona o ingresso no ensino superior. Por sua vez, $25 \%$ da escola pública comenta que seu sonho profissional é obter sucesso profissional, ao passo que $32 \%$ dos estudantes da rede particular externaram a mesma resposta. Já $4 \%$ dos estudantes da escola pública responderam que seu sonho profissional é sobreviver a tudo isso. Embora o questionário aberto permitisse que os estudantes fornecessem múltiplas respostas, tanto alunos da pública quanto da particular deram apenas uma. Os sonhos dos mais vulneráveis estão mudando e o índice de estudantes da escola pública que pretende entrar em uma universidade contraria dados de outra pesquisa, a qual mostra maior busca pela universidade por parte de estudantes de escolas particulares (Sparta \& Gomes, 2005). 
Para alcançar seus sonhos profissionais, $88 \%$ dos alunos dos alunos das escolas públicas e particular sinalizou o poder da educação, tornando a escola uma instituição de referência na formação humana, afirmando que, para não pensar bobagens, se dedica ao ERE. Os outros $12 \%$ da rede pública sinaliza que faz cursos profissionalizantes e os $12 \%$ da particular está totalmente sem perspectiva. De acordo com Foucault (1979), a população, por meio do sujeito mostra suas aspirações, consciente daquilo que se quer, mas inconsciente daquilo que quer que a instituição faça. Dessa forma, governar e programar políticas públicas perpassa pelas necessidades da sociedade, identificadas não só pelo aspecto quantitativo de demanda, mas pelo aspecto qualitativo para garantir a sua sustentabilidade. Por outro lado, um grupo da escola pública (12\%) indicou que esse caminho seria alcançado estudando e buscando qualificação, enquanto estudantes da instituição particular (12\%) assinalaram não saber/não ter perspectiva.

Para Bourdieu (1998), a sociedade entende que a posse de capital cultural favoreceria o desempenho escolar na medida em que funcionasse como uma ponte entre o mundo familiar e a cultura escolar, assim como propiciaria um melhor desempenho nos processos formais e informais de avaliação. O problema é que os sonhos dependem de certas avaliações para se concretizarem e, estas, vão além de uma simples verificação de aprendizagem porque cobram estilos de fala, escrita e comportamentos, totalmente dependentes de certos valores familiares.

A análise dos dados sobre as angústias envolvendo a temática da saúde na atualidade revelou números preocupantes, que reforçam a constatação de que a pandemia tem afetado a saúde mental da juventude: $39 \%$ dos alunos da escola pública e $34 \%$ da particular revelaram insegurança com o futuro; $30 \%$ da pública e $22 \%$ da particular demonstram angústia com a continuidade de doenças oriundas da pandemia; $22 \%$ da escola pública e da particular expressam sua angústia quanto à sociedade não ter aprendido nada; $13 \%$ da escola pública e $11 \%$ da particular afirmaram não saber o que pensar. Em relação às angústias sobre futuro profissional, $43 \%$ de alunos de escolas públicas e $27 \%$ de alunos da escola particular temem não entrar na faculdade. Vinte e seis por cento dos alunos de escolas públicas temem não entrar no mercado de trabalho, enquanto $4 \%$ destes e $27 \%$ de alunos de escola particular temem não se manter no mercado de trabalho. Nove por cento dos alunos das públicas e 19\% da particular temem não concluir o EM. Treze por cento dos alunos das públicas e $27 \%$ da particular temem não ter saúde para estudar ou trabalhar no futuro próximo.

Mesmo com aumento de vagas para o ensino superior nos últimos cinquenta anos, concorda-se com Zago (2006) quando este comenta que muitos jovens estão em processo de desenvolver estratégias integradoras para se opor ao processo de exclusão e vencer os processos avaliativos no início da vida adulta. Para Foucault (2008), o exame acaba por transformar a formação do saber em um exercício de poder diferencial, já que: a) o exame inverte a economia da visibilidade do exercício da força (a força do poder não está no discurso, mas na visibilidade disciplinada dos súditos); b) o exame faz a individualidade entrar num campo documentário (o exame coloca os indivíduos num campo de vigilância, em que os documentos escritos captam, classificam, qualificam, quantificam e fixam os resultados sobre os indivíduos); c) o exame faz de cada indivíduo um caso (faz o ser virar um objeto não definido pelas circunstâncias que o qualificam, mas pelo modo como o indivíduo é comparado). 
Segundo o Instituto Brasileiro de Geografia e Estatística (2019), o insucesso nessa transição do ensino médio para o superior pode dificultar os jovens a atingir outros objetivos inerentes à fase adulta, influenciando seu grau de satisfação com a vida, confiança em outras pessoas e até interesse na política. Por outro lado, segundo dados de Polanczyk (2020), frente a traumas de saúde, aparece um aumento dos índices de impotência dos jovens que leva a transtornos mentais e até ao suicídio. Houve um número inferior ao sinalizado por Zan \& Krawczyk (2020) de alunos que temem não concluir a educação básica, mas este retorno ainda é preocupante porque se está em pandemia e se eles não adaptarem ao ERE, muitos estudantes de baixa renda abandonarão a escola, piorando o quadro de que pessoas sem escolaridade recebem $20 \%$ menos quando ingressam no mercado de trabalho (Instituto Brasileiro de Geografia e Estatística, 2019). Como lembra Bourdieu (1992), as representações individuais criam uma concepção ilusória de que os sujeitos têm excessiva autonomia na condução de suas ações, afirmando que as atitudes e comportamentos (futuro profissional inclusive) dependem do que é socialmente constituído para os jovens. A dádiva/ troca vivida pelas sociedades elementares, desejada pelas sociedades modernas, que permite prestações de sentimentos, volições e crenças, por um lado, e movimento corporal trabalhado no e pelo coletivo, por outro (Mauss, 2017), só acontece quando há paridades entre os sujeitos que dão, recebem e retribuem saberes. Caso contrário, só se aumenta as discriminações e com elas, as possibilidades de segregação social.

\section{CONCLUSÃO}

A partir das inferências do estudo, percebe-se a importância do debate sobre saúde dos formandos dos 30 anos do EM. Durante o acompanhamento online das notícias governamentais, os alunos se sentem impotentes, tristes, com raiva, ansiosos e desmotivados frente ao que os profissionais e entidades têm sugerido para o espaço público que não teve total aprovação no privado, mostrando despreocupação com as condições socioeconômicas de grande parte da população.

Por meio de redes sociais (WhatsApp, Instagram, Youtube, Facebook e Twitter), os estudantes permanecem na internet por muitas horas a fim de acompanhar temas de saúde, política ou assuntos gerais, destinando mais de quatro horas, por dia, somente para os estudos. No entanto, aqueles que nem acessam a internet, ficam prejudicados frente às determinações do Ministério de Educação, sem participar das pesquisas que levantem as necessidades dos jovens, sem contar com movimentos dos colegas de classe para garantir o direito de todos a uma educação de qualidade.

Os sonhos estão se modificando na medida as reportagens sinalizam que os estudantes devem se preocupar com seus futuros de forma individualizada, já que não é compartilhado um projeto governamental que atenda as demandas da população nem um projeto comunitário que instigue tais discussões. As maiores angústias se referem às preocupações com a saúde pública e com a sua própria, pois, caso desenvolvam sequelas de contaminação pelo COVID-19, poderão ter dificuldade de arrumar um emprego ou permanecer em um emprego formal; com o aumento da chance de não concluir o EM ou não ingressar na universidade, demandas que poderiam favorecê- 
los financeiramente no futuro e que estão intrinsecamente relacionadas aos sonhos de ter uma formação; ou, com a possibilidade de não ter sucesso profissional. Como alternativa, um grupo de alunos sinaliza que vem estudando para não pensar no momento histórico.

É preciso observar que se vive uma política nacional de extermínio. Enquanto, em março, líderes mundiais foram à TV anunciar o lockdown (distanciamento social com bloqueio total das pessoas pelas ruas), no Brasil, sem fontes científicas que dessem conta dos discursos do presidente, havia o discurso de que a imunidade de rebanho ${ }^{13}$ salvaria a pátria. Agravando a situação, o presidente tentou cortar o bolsa família (Martins, 2020b) e propôs a maior taxa do mundo de tributação sobre os mais pobres (TV GNN, 2020), com total apoio do BBB $^{14}$ que hoje representa o maior número de deputados e senadores do Congresso. Por medida e portaria, o governo flexibiliza a carga horária escolar, além de pressionar a população a voltar às aulas presenciais, deixando evidente que permitir que os estudantes fiquem seguros, não é uma prioridade.

Como lembra Foucault (1979), a constituição de governamentalidade implica analisar as formas de racionalidade sobre o que é essencial para o bem-estar, sendo as propriedades, riquezas, recursos as variáveis pertinentes de cada território e que dão suporte ao suprimento das necessidades da população. Passada a época do principado de Maquiavel, com a ideia de Estado tal como se tem hoje, devem-se analisar os movimentos de concentração estatal e dispersão religiosa, pois não está sendo fácil acompanhar os rumos da educação por viesses de outros valores que não sejam pedagógicos.

Por mais que se democratize o acesso ao ensino por meio da escola pública e gratuita, continuará existindo uma forte correlação entre as desigualdades sociais, sobretudo, culturais, e as desigualdades ou hierarquias internas ao sistema de ensino (Bourdieu, 1992). Como a transmissão de costumes não é natural, pelo contrário, as condutas individuais nunca são simbólicas por si mesmas, mas elementos a partir dos quais se constrói um sistema que se consolida no coletivo (Mauss, 2017), se os alunos não compreenderem as diferentes modalidades do social, do individual e das possibilidades de expressão, eles não tornarão seus corpos fatos sociais totais. Esse caminho leva a uma segregação étnica na qual os negros pobres serão mais suscetíveis a desistir de estudar, a morrer, a adoecer, a ficar desemprego. Aqueles, por sua vez, que sobreviverem, terão dificuldades maiores para superar a atual conjuntura e, além disso, mais dificuldades para respeitar a democracia do país, igualmente jovem.

O texto colabora com os professores que estão realizando ERE, com gestores escolares, acadêmicos e graduandos interessados em pesquisar o tema, profissionais da saúde que lidam com tal faixa etária, familiares dos alunos que estão tentando estudar em casa, e, por fim, com os

\footnotetext{
13 Essa expressão tem sido utilizada pelo presidente do Brasil, remetendo ao surgimento da vacina, quando ordenhadores ingleses testaram prevenir a varíola bovina em suas aldeias, raspando as tetas das vacas doentes e colocando essas peles nos próprios braços e pernas. Com tal procedimento, houve imunização e estas pessoas não morreram no século XIX. A partir disso, cria-se a ideia de que a população precisa adquirir a doença para se imunizar, no entanto, segundo Leventi (2020) não há imunidade por rebanho, tendo em vista que, o vírus Covid-19 pode contaminar, novamente, a pessoa após três meses.

${ }^{14}$ BBB ou bancada do boi, bíblia e bala se refere aos grupos ruralistas, evangélicos e de segurança pública que dominam a representatividade na Câmara e no Senado (Kadanus, 2018) em Brasília.
} 
próprios alunos das escolas públicas e privadas que vêm se manifestando nas redes sociais. Pensase em acompanhar esses quatro grupos para averiguar se as condições de vida melhorarão a partir de governos mais comprometidos com a sociedade brasileira.

Esta reflexão científica precisa ser socializada, a amostra ampliada e as desvantagens ênfase na percepção do sujeito e pouco aprofundamento das questões - citadas por Gil (2009)-, superadas com novos aportes teórico-metodológicos, na própria cidade como em outros locais.

\section{REFERÊNCIAS}

Bardin, L. (1977). Análise de conteúdo. Lisboa: Edições 70.

Bourdieu, P. (1992). A reprodução. Rio de Janeiro: Francisco Alves.

Bourdieu, P. (1998). Escritos de Educação. Petrópolis: Vozes.

Constituição da República Federativa do Brasil (1988). Brasília: Diário Oficial da União. $\begin{array}{lllll}\text { Recuperado em } 28 & \text { maio, } & \text { de }\end{array}$ http://www.planalto.gov.br/ccivil_03/constituicao/constituicao.htm.

Bruyne, P. de, Herman, J., \& Schouthteete, M. de (1977). Dinâmica da pesquisa em ciências sociais: os polos da prática metodológica. Rio de Janeiro: Francisco Alves.

Cont, V. del (2008). Francis Galton: eugenia e hereditariedade. Scientiae Studia, 6 (2). Recuperado em 13 maio, 2020, de https://www.scielo.br/scielo.php?script=sci_arttext\&pid=S167831662008000200004 .

Duarte, C. P., \& Fernandes Jr., J. F. (2019). Técnicas de concentração, relaxamento e autoconsciência na escola pública: as experiências extracurriculares que colaboram com um currículo intercultural no ensino médio. Movimento Revista de Educação, 6 (11), 237-249. $\begin{array}{lllll}\text { Recuperado em } & 18 & \text { abril, }\end{array}$ https://periodicos.uff.br/revistamovimento/article/view/32890.

Foucault, M. (1979). Microfísica do poder. Organização e tradução de Roberto Machado. Rio de Janeiro: Edições Graal.

Foucault, M. (2008). Vigiar e punir: nascimento da prisão. Tradução de Raquel Ramalhete. Petrópolis: Vozes.

Galton, F. (1865). Hereditary talent and character. Macmillan's Magazine, 12, 157-166, 318-327. Recuperado em 11 dezembro, 2018, de http:/galton.org/essays/1860-1869/galton-1865macmillan-hereditary-talent.html.

Gil, A.C. (2009). Métodos e técnicas de pesquisa social (6a ed.). São Paulo: Atlas.

Instituto Brasileiro de Geografia e Estatística (2019). Síntese de indicadores sociais: uma análise das condições de vida da população brasileira. Rio de Janeiro: Instituto Brasileiro de Geografia e Estatística. 
Jucá, B. (2019, setembro 9). Cortes de verbas desmontam ciência brasileira e restringem pesquisa a mais ricos. EI País, São Paulo. Recuperado em 29 maio, 2020, de https://brasil.elpais.com/brasil/2019/09/03/politica/1567542296_718545.html.

Kadanus, K. (2018, outubro 4). Bancada Evangélica é a terceira maior do Congresso e atua em bloco. Gazeta do Povo, Curitiba. Recuperado em 1 novembro, 2020, de https://www.gazetadopovo.com.br/politica/republica/eleicoes-2018/bancada-evangelica-ea-terceira-maior-do-congresso-e-atua-em-bloco-3fipxwil0cmqqw7mgx6js3982/.

Kafruni, S. (2020, março 30). Senado aprova auxílio emergencial de $\mathrm{R} \$ 600$ a pessoas de baixa renda. Correio Braziliense, Brasília. Recuperado em 29 maio, 2020, de https://www.correiobraziliense.com.br/app/noticia/politica/2020/03/30/interna_politica,84 1296/senado-aprova-auxilio-emergencial-de-r-600-a-pessoas-de-baixa-renda.shtml.

Lei n. 9.394, de 20 de dezembro de 1996 (1996). Estabelece as Diretrizes e Bases da Educação Nacional. Brasília: Diário Oficial da União.

Leventi, A. (2020, agosto 9). Segunda onda de Covid está perto, alerta cientista do Inpa. D24am, Manaus. Recuperado em 11 agosto, 2020, de https://d24am.com/amazonas/segunda-ondade-covid-esta-perto-alerta-cientista-do-inpa/.

Martins, H. (2020a, março 24). Bolsonaro crítica 'histeria' com coronavírus: 'Devemos voltar à normalidade'. Estado de Minas, Belo Horizonte. Recuperado em 29 maio, 2020, de https://www.em.com.br/app/noticia/politica/2020/03/24/interna_politica,1132126/bolsona ro-critica-histeria-com-gripezinha-do-coronavirus.shtml.

Martins, L. (2020b, agosto 5). STF decide que governo não pode cortar Bolsa Família durante a pandemia. Valor, Brasília. Recuperado em 10 agosto, 2020, de https://valor.globo.com/politica/noticia/2020/08/05/stf-decide-que-governo-nao-podecortar-bolsa-familia-durante-a-pandemia.ghtml.

Mauss, M. (2017). Ensaio sobre a dádiva. Lisboa: Edições 70.

Mendonça, E. de S., Correio, D. B. A. de A., \& Correio, C. M. B. de H. (2016). Juventude (des)politizada? Ampliando perspectivas no olhar a participação política juvenil. Revista Psicologia Política, 16 (35), 87-102. Recuperado em 10 julho, 2020, de http://pepsic.bvsalud.org/scielo.php?script=sci_arttext\&pid=S1519-549X2016000100006.

Mozzato, A. R., \& Grzybovski, D. (2011). Análise de conteúdo como técnica de análise de dados qualitativos no campo da administração: potencial e desafios. Revista de Administração Contemporânea, 15 (4), 731-747. Recuperado em 26 outubro, 2020, de https://doi.org/10.1590/S1415-65552011000400010.

Oliveira, J. (2019, agosto 13). Estudantes voltam às ruas contra o bloqueio do Orçamento de universidades. El País, São Paulo. Recuperado em 29 maio, 2020, de https://brasil.elpais.com/brasil/2019/08/13/politica/1565649573_655949.html. 
Ornell, F., Schuch, J. B., Sordi, A. O., \& Kessler, F. H. P. (2020). "Pandemic fear" and COVID-19: mental health burden and strategies. Brazilian Journal of Psychiatry, 42 (3), 232-235. $\begin{array}{lllll}\text { Recuperado em } & 13 & \text { julho, } & \text { de }\end{array}$ https://www.scielo.br/scielo.php?script=sci_arttext\&pid=S1516-44462020000300232.

Pimentel, C. (2018, outubro 28). Veja as propostas de governo do presidente eleito Jair Bolsonaro. Agência Brasil, Brasília. Recuperado em 4 junho, 2020, de https://agenciabrasil.ebc.com.br/politica/noticia/2018-10/veja-propostas-de-governo-dejair-bolsonaro.

Polanczyk, G. V. (2020, maio 11). O custo da pandemia sobre a saúde mental de crianças e adolescentes. Jornal da USP, São Paulo. Recuperado em 13 julho, 2020, de https://jornal.usp.br/artigos/o-custo-da-pandemia-sobre-a-saude-mental-de-criancas-eadolescentes/?fbclid=IwAR3YHSEXINXa_a-lowyTf1c80t727eDSiT5fvj49PIljx7YDsHkXcm74Khg.

Portaria n. 343, de 17 de março de 2020 (2020). Dispõe sobre a substituição das aulas presenciais por aulas em meios digitais enquanto durar a situação de pandemia do Novo Coronavírus COVID-19. Brasília: Diário Oficial da União. Recuperado em 20 maio, 2020, de http://www.in.gov.br/en/web/dou/-/portaria-n-343-de-17-de-marco-de-2020-248564376.

Rede TVT (2020). Bolsonaro tenta alterar a bula da cloroquina no Brasil [Vídeo]. Recuperado em 23 maio, 2020, de https://www.youtube.com/watch?v=yNj52OIShBQ.

Rodrigues, S. (2019, dezembro 17). Retrospectiva: Governo tentou desacreditar o INPE. O Eco. Recuperado em 29 maio, 2020, de https://www.oeco.org.br/noticias/retrospectiva-governotentou-desacreditar-o-inpe/.

Salas, J. (2017, maio 22). Instagram é a pior rede para a saúde mental dos adolescentes. El País, Madri. Recuperado em 25 maio, 2020, de https://brasil.elpais.com/brasil/2017/05/19/tecnologia/1495189858_566160.html.

Sparta, M., \& Gomes, W. B. (2005). Importância atribuída ao ingresso na educação superior por alunos do ensino médio. Revista Brasileira de Orientação Profissional, 6 (2), 153-166. Recuperado em 15 julho, 2020, de http://pepsic.bvsalud.org/scielo.php?script=sci_arttext\&pid=S1679-33902005000200005.

TV GNN (2020). Brasil poderá ser o primeiro no mundo em taxação de grandes pobrezas [Vídeo]. Recuperado em 11 agosto, 2020, de https://www. youtube.com/watch?v=6qyml6w7cAw.

Urquiza, M. de A., \& Marques, D. B. (2016). Análise de conteúdo em termos de Bardin aplicada à comunicação sob o signo de uma abordagem teórico-empírica. Entretextos, 16 (1), 115-144.

Vermelho, S. C., Velho, A. P. M., Bonkovoski, A., \& Pirola, A. (2014). Refletindo sobre as redes sociais digitais. Educação \& Sociedade, 35 (126). Recuperado em 18 maio, 2020, de https://www.scielo.br/scielo.php?pid=S0101-73302014000100011\&script=sci_arttext.

Zajac, D. (2020). Ensino remoto na Educação Básica e COVID-19: um agravo ao Direito à Educação e outros impasses. Santo André: Escola preparatória da Universidade Federal do ABC/ Pró- 
reitoria de Extensão e Cultura. Recuperado em 17 maio, 2020, de http://proec.ufabc.edu.br/epufabc/ensino-remoto-na-educacao-basica/.

Zago, N. (2006). Do acesso à permanência no ensino superior: percursos de estudantes universitários de camadas populares. Revista Brasileira de Educação, 11 (32). Recuperado em 15 julho, 2020, de https://www.scielo.br/pdf/rbedu/v11n32/a03v11n32.pdf.

Zan, D., \& Krawczyk, N. (2020, julho 3). Educação e Juventude sob Fortes Ameaças. Anped, Rio de Janeiro. Recuperado em 3 julho, 2020, de http://www.anped.org.br/news/educacao-ejuventude-sob-fortes-ameacas-colaboracao-de-texto-por-dirce-zan-unicamp-gt-03-nora.

\section{COMO CITAR ESTE ARTIGO:}

Duarte, C. P. (2020). Efeitos dos comunicados governamentais sobre saúde em tempos de pandemia por Covid-19 nos alunos de 3os anos do ensino médio de escolas públicas e privadas de Juiz de Fora. Holos. 36(5), 1-14.

\section{SOBRE OS AUTORES}

\section{P. DUARTE}

Professora titular do Departamento de Educação Física do Colégio de Aplicação João XXIII - Universidade Federal de Juiz de Fora. E-mail: catia.duarte@ufjf.edu.br

ORCID ID: https://orcid.org/0000-0003-3671-0867

Editor(a) Responsável: Leandro Costa

Pareceristas Ad Hoc: LENINA SILVA E ADRIANA APARECIDA DE SOUZA

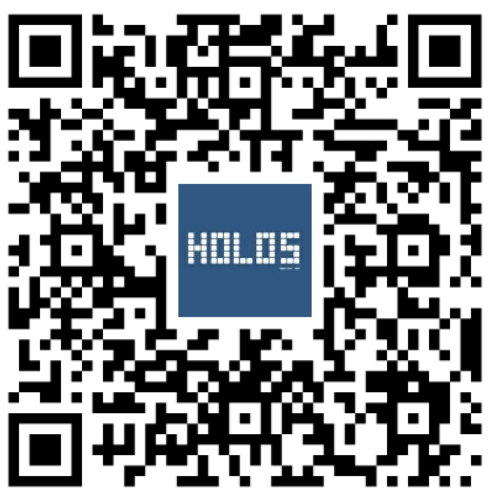

